\title{
Treliças eșpaciais metálicas: incorporação de requisitos de dimensionamento aos estágios iniciais do design paramétrico
}

Spatial steel trusses: Integrating structural pre-dimensioning requirements

in the early stages of the parametric design

> André L. Araujo

University of Campinas, Brazil

a.araujo@fec.unicamp.br

> Gabriela Celani

University of Campinas, Brazil

celani@fec.unicamp.brld

\author{
> Wilson Barbosa Neto \\ University of Campinas, Brazil \\ wbarbosa@fec.unicamp.br
}

\begin{abstract}
The integration of structural considerations in architectural geometry processing is among the topics most discussed in the complex shapes design. While some design tools allow the designer to begin with an inefficient form and then turn it into a more efficient one, other tools allow exploring and creating structural forms considering both formal and structural aspects from the beginning. This paper presents a parametric design approach to create spatial steel trusses with the combination of two strategies: (1) shell surface to set out structural elements; (2) cross section properties to ensure structural stability aspects. In this paper we discuss how the combination of these strategies can contribute to the use of parametric design techniques in the early stages of the design process, taking into account both structural optimization and production aspects.
\end{abstract}

Keywords: Structural design; Spatial Structures; Tubular trusses; Parametric Design; Dimensioning

\section{Introdução}

Desde a publicação da obra Performative Architecture: Beyond Instrumentality (Kolarevic, Malkawi, 2005), os arquitetos têm se preocupado cada vez mais em utilizar o bom desempenho como um princípio norteador do projeto. Essa conduta sempre esteve presente na obra dos principais arquitetos da história, mas, segundo esses autores, a disponibilidade atual de programas de simulação facilitou enormemente a incorporação dos resultados das análises de desempenho - em especial o ambiental e o estrutural - nas etapas iniciais de projeto. No entanto, a retroalimentaçáo dos resultados dessas análises nem sempre é feita de maneira automatizada, pois isso exige o desenvolvimento de programas com capacidades generativas, o que implica necessariamente na adoção de condutas projetuais específicas. Em outras palavras, em um cenário ideal, o projetista deveria ser capaz de programar suas próprias ferramentas, de modo a obter a automatizaçáo da incorporação do resultado das análises em seu processo de projeto.

As estratégias de design paramétricas e generativas estáo fortemente relacionadas aos aspectos de controle da forma geométrica e, consequentemente, à produçáo de diversas soluçóes de projeto balizadas por parâmetros definidos pelo próprio projetista. No entanto, em muitas situaçôes, os aspectos produtivos das soluçôes arquitetônicas ficam em parte comprometidos quando se consideram as propriedades dos materiais somente de modo subsequente à concepção formal. No design de arquitetura, uma situação mais interessante é o controle paramétrico não só nos domínios formais, mas sobretudo, a conjugação destes com o controle das proprie- dades dos materiais. Isso permite, por exemplo, que decisóes do âmbito produtivo norteiem também a parametrização proposta pelo projetista.

Um dos principais propósitos de uma plataforma paramétrica de projeto é se adaptar ao estilo, às preferências e aos objetivos do arquiteto, que podem mudar constantemente durante o processo. De modo alinhado a essa tendência, alguns programas de simulação estrutural já possuem uma vinculação direta com os de modelagem paramétrica, funcionando de maneira dinâmica, isto é, a cada nova forma proposta formal, novos cenários estruturais são esboçados. Além da adaptação às condições estruturais, os processos de projeto assistidos por ferramentas de análise e simulação podem expandir a criatividade e a habilidade de resolver problemas (Shea, 1999). Embora cada projetista tenha um estilo diferente, fundamentado em seu repertório de formas e em sua visão sobre a funcionalidade, essas ferramentas podem evidenciar situaçóes e aumentar a percepção nos processos criativos.

Dentre as decisóes mais tradicionais no design de estruturas (a escolha do material, da seção transversal do elemento, das posiçóes dos nós, da geometria global, da topologia e das condiçôes de apoio), a geometria global é a principal definidora dos aspectos da estabilidade, funcionalidade e segurança (Andriaenssen, 2012). Mesmo assim, essa preponderância pode ser observada de diferentes maneiras, nos diferentes tipos de estruturas. No exemplo das estruturas de malha orientada segundo uma superfície (grid shells), as deformaçóes excessivas nos planos transversais à superfície devem ser evitadas. É comum nesses projetos a determinação da superfície e, 
posteriormente, a definição da posiçáo dos nós de modo otimizado (Richardson, et al. 2013). Nas estruturas treliçadas, a otimização não tem o mesmo papel. Embora ela conduza a uma melhora da estabilidade, seu intuito é, fundamentalmente, orientar a inserção, a remoção ou a posição de montantes e de diagonais. Assim, a geometria global pode receber mudanças que vão desde pequenas inclinaçóes de elementos até alteraçóes no partido arquitetônico pretendido.

$\mathrm{Na}$ questão do refinamento da solução estrutural, as técnicas de otimização que utilizam elementos finitos têm demonstrado um grande potencial nos últimos anos. Isso tem permitido ao projetista iniciar o projeto com uma forma estruturalmente ineficiente e então buscar a sua eficiência, geralmente minimizando tensóes de flexão. De acordo com Kilian \& Ochsendorf (2005) a utilização dessa técnica tem sido cada vez mais frequente, embora ainda sejam poucas as ferramentas computacionais que exploram aspectos da criação de novas formas estruturais. Pottmann et al. (2007) vão além ao mencionar que as novas propostas estruturais podem ser apreciadas pela inventividade, plasticidade ou geraçáo de malhas, mas não por sua consideração de cargas gravitacionais. Na visão desses autores, a integração das consideraçôes estruturais no processo de projeto de arquiteturas complexas estão entre os tópicos ainda pouco explorados pelas pesquisas na área de design computacional.

A fim de explorar alternativas para essa problemática, o presente artigo apresenta uma investigaçáo computacional, na qual se objetivou desenvolver um sistema para a geração de treliças espaciais paramétricas, combinando parâmetros relacionados à forma global e às propriedades das seçóes transversais dos elementos. A partir dos resultados, discutiu-se a influência dessa estratégia nos estágios iniciais do processo de projeto. Tecendo-se conjecturas sobre as contribuiçóes dessa combinação de parâmetros, apontaram-se perspectivas para pesquisas que busquem a abordagem de aspectos produtivos nos ambientes de design paramétrico. Este artigo apresenta um exemplo do desenvolvimento de uma ferramenta desse tipo que lida, especificamente, com o projeto de treliças espaciais metálicas.

\section{Implementação computacional}

A investigação computacional proposta buscou integrar técnicas de design paramétrico e alguns requisitos de dimensionamento de treliças espaciais tubulares de aço. Com o uso de linguagens de programação visual e textual em um ambiente CAD, foram desenvolvidos quatro procedimentos de parametrização (Figura 1): (1) definição de uma superfície geométrica controlada por duas de suas diretrizes opostas, definidas por funçôes trigonométricas; (2) determinação dos elementos da treliça, banzos e diagonais, com base em regras topológicas; (3) utilização de um banco de dados com propriedades geométricas das seções tubulares; (4) programação de restriçốes, com base em procedimentos de cálculo constantes da norma brasileira.

A modelagem paramétrica das treliças foi executada com o aplicativo Rhinoceros, versão 5 de 64-Bit, e o add-on Grasshopper, na versão 1.0 com a atualização 0.9.0056 de 2013 (McNeel \& Associates, Inc.). Para a restriçóes, programaram-se duas limitaçóes de dimensionamento utilizando-se a linguagem de programaçáo C\# no

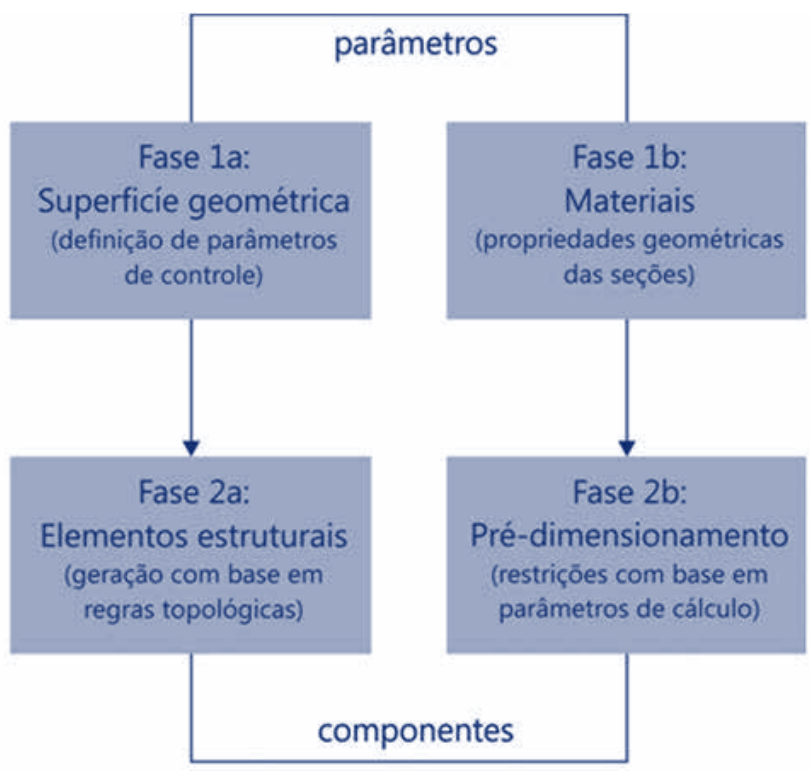

Fig. l: Procedimentos propostos para a exploração computacional.

ambiente Visual Studio 2010 (Microsoft, Inc.) e, posteriormente, vinculando-a ao ambiente do Rhinoceros por meio de componentes específicos para este fim.

Os requisitos de dimensionamento selecionados foram: (1) limitação da inclinação das diagonais proposta pela norma NBR/ CB-02 (ABNT, 2011), que sugere que os ângulos entre o banzo inferior e as diagonais não sejam inferiores a $30^{\circ}$; e (2) a limitação da esbeltez das diagonais, com base no índice de esbeltez para barras bi-articuladas, proposto pela NBR8800 (ABNT, 2012), no qual o limite " $\mathrm{Kl} / \mathrm{r}$ " para barras comprimidas não pode ser superior a 200. Os materiais utilizados para essas verificaçóes foram os perfis tubulares circulares sem costura, cujas propriedades geométricas constam dos catálogos da siderúrgica Vallourec \& Mannesmann (V\&M), predominante no mercado brasileiro.

\section{Estratégias: Fases la e $2 a$}

Dentre as várias maneiras de se obter uma superfície controlada, nesta investigaçáo computacional optou-se pela definição de duas curvas diretrizes dispostas em planos paralelos e obtidas por pontos. A ideia que balizou esse procedimento foi que a variaçáo na posição dos pontos implicasse na mudança da configuraçáo da superfície. Apenas por questóes de simplificação analítica, os pontos variaram de posição nas direçóes dos eixos ortogonais x e z, de modo que a projeçáo horizontal da superfície (no plano xy) formasse sempre um retângulo. Dentre as duas opçóes predominantes de curvas, controladas por pontos externos ou pertencentes à curva, essa última se mostrou mais conveniente, uma vez que os pontos contidos na curvas poderiam representar também os nós estruturais. Para um efeito similar, é possível projetar os pontos de controle das B-Splines sobre elas mesmas, o que implica em um procedimento adicional.

Embora os pontos de controle possam ser definidos de maneira aleatória, a possibilidade de vincula-los como contra-domínios de uma função matemática apresenta certa conveniência, pois incrementa um 

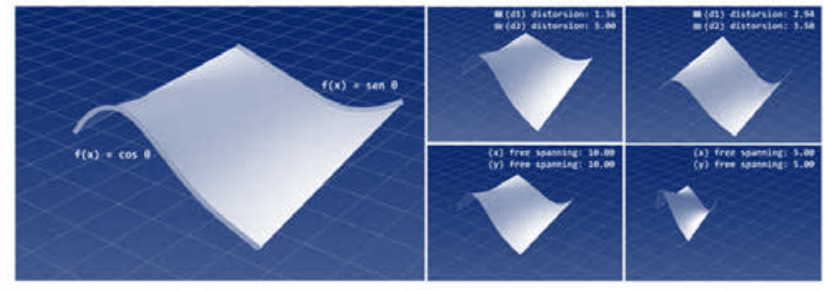

Fig. 2: Controle paramétrico da superfície que define a treliça.

modo de controle no processo. Com esse objetivo, as funçóes seno e coseno foram utilizadas como definidoras para as diretrizes opostas. Os domínios dessas funções foram definidos por séries matemáticas simples. Desse modo, obteve-se uma quantidade de algarismos reais e as diferenças entre os algarismos e seus antecessores (passo). Os contra-domínios das funçóes forneceram as coordenadas z das curvas, enquanto a própria série de números abasteceu as coordenadas $\mathrm{x}$. $\mathrm{O}$ efeito dessas opçôes é um sistema no qual a configuração das curvas estão sempre distorcendo a superfície pela quantidade de pontos de controle, desde que estes sejam maiores do que 1. Havendo apenas um contra-domínio para as funçōes, obtém-se um plano ao invés de uma superfície, o que pode ser também uma solução interessante para alguns problemas de projeto. A largura e o comprimento da superfície foram determinados fornecendo valores para os pontos finais das curvas (Figura. 2).

A definição dos elementos estruturais baseada na superfície obtida seguiu algumas regras. Dividiu-se inicialmente a superfície segundo as direçóes de dois vetores unitários "u" e "v". Essas divisóes geraram uma malha quadrada, cujas linhas serviram de eixos para os elementos do banzo superior da treliça. Os demais elementos estruturais foram obtidos a partir da definição de uma regra tipológica. Essa regra consistiu de um schema cuja forma repetitiva foram semi-octaedros de base retangular (pirâmides invertidas). Esse

Fig. 3: Treliça multiplanar do aeroporto de Hannover. Fonte: http://www. hannover-airport.de/.

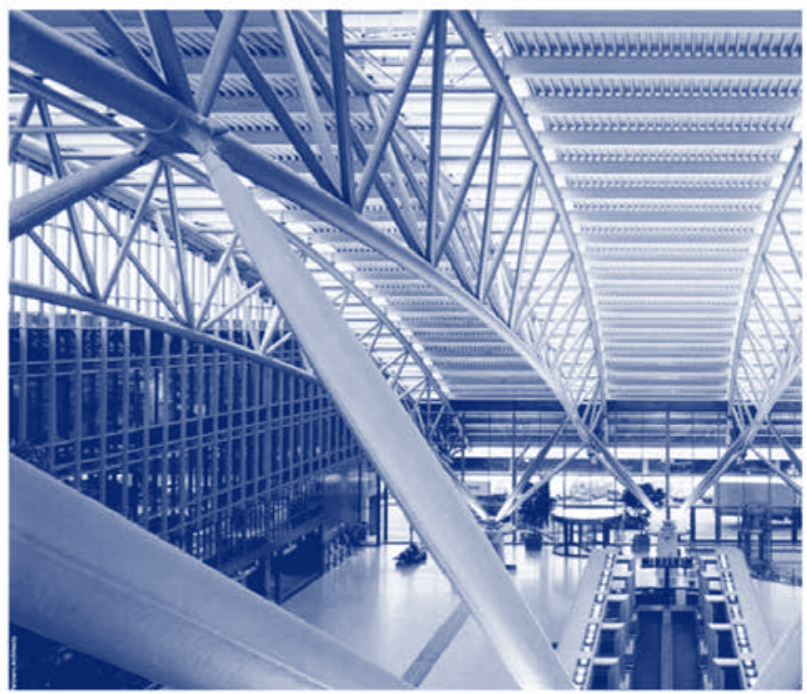

schema é frequentemente utilizado em treliças multiplanares, nas quais são repetidas suas formas e tamanhos, recebendo a denominação de "módulo" (Fig. 3). Aqui, propuseram-se "módulos" com repetição somente da forma poliédrica, variando constantemente os tamanhos e as inclinaçôes das arestas, denominados schema (no plural, schemata). As arestas dos schemata serviram como eixos para as diagonais da treliça, enquanto nos vértices foram definidos os nós.

\section{Estratégias: Fases lb e 2b}

A parametrização das propriedades dos materiais consistiu em fornecer ao modelo informaçóes dos elementos a serem utilizados na produção das treliças. Selecionaram-se as propriedades geométricas dos perfis tubulares circulares de aço sem costura, obtidas nos catálogos da siderúrgica Vallourec \& Mannesmann, predominantes no mercado brasileiro. Além do uso amplamente difundido em treliças, a seção circular apresenta níveis superiores de resistência à flambagem quando submetida à compressão em comparação a outras seçôes. Isso se dá porque sua forma é a única de completa simetria em qualquer direçáo que passe pelo seu centro de gravidade. Em síntese, isso equivale a dizer que a circunferência é a única linha que possui todos os seus pontos equidistantes de seu centro. Devido a essa simetria radial, aplicando-se uma força de compressão no centro geométrico e perpendicular à seção circular, todas as tensôes percorrerão as mesmas distâncias, evitando-se, assim, assimetrias ou direçôes preferenciais para que ocorra flambagem. Outros perfis tubulares de seção duplamente simétrica, como é o caso da seção quadrada, foram preteridos por apresentarem diferenças geométricas quando rotacionados e comparados em diferentes posiçóes segundo o mesmo par de coordenadas e, nesta investigação, buscou-se uma simplificação dos aspectos conceituais da estrutura. Na Tabela 1são apresentadas as propriedades geométricas de quatro perfis tubulares V\&M utilizados no banco de dados. No total, forneceram-se 21 perfis com variaçóes de tamanho e espessura (Tabela 1).

Tabela 1: Propriedades geométricas dos perfis de seção circular.

\begin{tabular}{|c|c|c|c|c|c|c|c|c|}
\hline 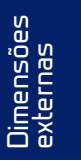 & 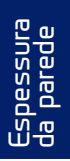 & 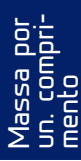 & 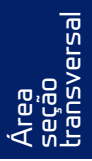 & 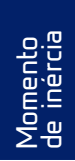 & 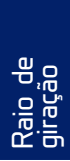 & 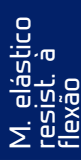 & 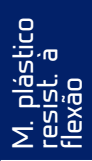 & $\begin{array}{l}\text { 은 } \\
\text { 妾 } \\
\text { 민 }\end{array}$ \\
\hline 73,0 & 7,1 & 11,50 & 14,70 & 80,7 & 2,34 & 22,10 & 31,00 & 0,229 \\
\hline 88,9 & 8,0 & 16,00 & 20,30 & 168,0 & 2,87 & 37,80 & 52,50 & 0,279 \\
\hline 101,6 & 8,0 & 18,50 & 23,50 & 260,0 & 3,32 & 51,10 & 70,30 & 0,319 \\
\hline 114,3 & 8,8 & 22,90 & 29,20 & 409,0 & 3,74 & 71,50 & 98,20 & 0,359 \\
\hline
\end{tabular}

A primeira restrição programada foi a limitação da inclinação das diagonais propostas pelo projeto de norma NBR/CB-02 (ABNT, 2011). Para a validade dos procedimentos de cálculo, essa norma sugere que os ângulos $\bigotimes$ entre o banzo e as diagonais e entre montantes e diagonais não sejam inferiores a $30^{\circ}$. Os casos contemplados por esse projeto de norma se concentram no dimensionamento de treliças planas e multiplanares, com vistas, principalmente, ao cálculo das ligaçóes. Como experimentação, utilizaram-se os mesmos critérios, uma vez que não existem normas técnicas específicas 


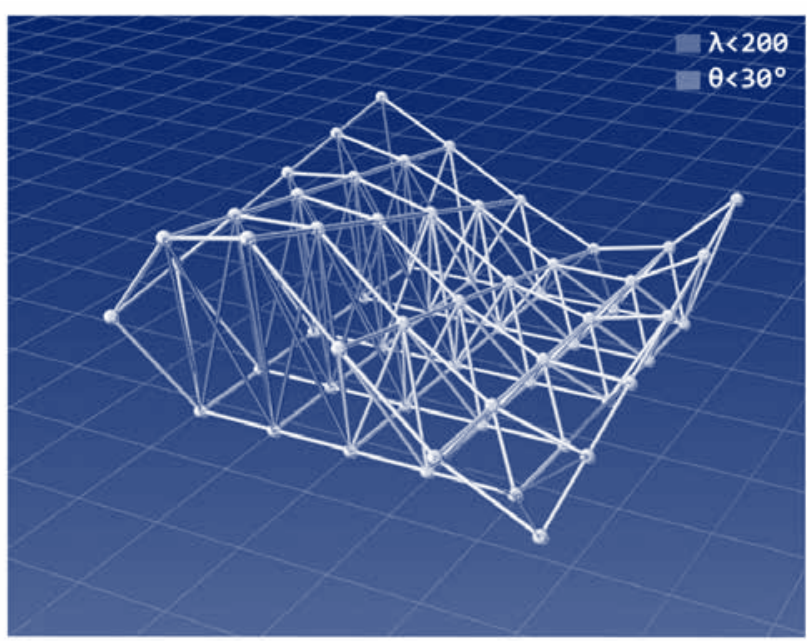

Fig. 4: Implementação de requisitos como parâmetros da exploração formal.

para as treliças espaciais. A rigor, a limitação dessa inclinação se aplicaria aos ângulos esféricos formados entre as quatro diagonais e o banzo inferior. Tendo em vista a dificuldade de mensurar tais ângulos, propôs-se dimensionar a inclinação entre uma diagonal e a barra do banzo inferior, o que equivale a uma aproximaçáo satisfatória. Além disso, com base na mesma limitação de ângulos, estabeleceu-se um limite superior de $60^{\circ}$ para as diagonais, a fim de não aproximá-las das características dos montantes.

Outra restrição programada foi fundamentada na aplicação do conceito de estabilidade na compressáo axial das diagonais. Segundo a NBR8800 (ABNT, 2012), para os elementos de comprimento $l$, da mesma ordem de diâmetro $D$, náo deve ocorrer a perda de estabilidade. Por definição, a carga crítica de flambagem, $F_{C R}$, ou carga de Euller, é o valor da carga $F$ que provoca o fenômeno da mudança do estado de equilíbrio estável para o instável. Nesse experimento, definiu-se uma condição de variação para $F_{C R}$, apenas para a teoria de $1^{\mathrm{a}}$ ordem, na qual não se consideram os deslocamentos horizontais no estudo do equilíbrio da estrutura. A partir daí, propôs-se limitar a esbeltez das diagonais, com base no índice de esbeltez para barras bi-articuladas. Hipoteticamente, idealizouse uma barra de seção constante inicialmente reta, mantida em sua posição original e deformada por uma carga axial $F$. A direção das ordenadas da elástica será a direção da menor rigidez contra flexão, lembrando que a seção circular é duplamente simétrica. Para cada um dos eixos tem-se: $N_{e}=\left(A_{g} f_{y}\right) \lambda^{2}$, onde $\lambda$ foi determinado conforme o item 5.3.4 da norma técnica, que define que o índice de esbeltez limite "Kl/r", para barras comprimidas, não pode ser superior a 200 .

As propriedades geométricas dos perfis serviram então como parâmetros para os componentes "limite de inclinação" e "limite de esbeltez". Assim, obteve-se um sistema paramétrico, no qual as distorçôes da forma geométrica forneceram diferentes cenários estruturais instantaneamente. A verificação desses dois limites funcionou como um indicativo ao projetista de uma situação de instabilidade, a qual pode ser solucionada de diversas maneiras: novas distorçóes para a superfície geométrica, aumento do número de divisóes da

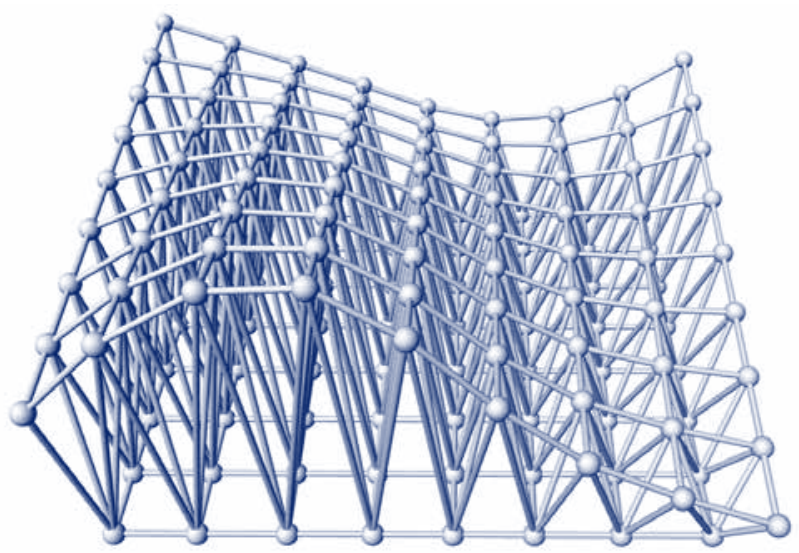

Fig. 5: Exemplo de uma treliça espacial obtida com o processo proposto.

treliça, aumento da altura da treliça, ou aumento do diâmetro e espessura do tubo (este último somente como solução ao limite de esbeltez). Na Figura 4 é apresentado o resultado da modelagem paramétrica de uma treliça espacial utilizando o sistema proposto, na qual foram identificadas regiôes de inclinaçôes inferiores a $30^{\circ}$ e diagonais esbeltas.

Modificando-se alguns parâmetros foi possível melhorar a configuração da treliça espacial mostrada na Figura 4, com relação aos limites programados. Inicialmente, para o vão proposto de $1500 \times 1500 \mathrm{~mm}$, a treliça foi dividida em 5x5 schemata, com diagonais de altura máxima igual a $200 \mathrm{~mm}$. A partir daí, algumas estratégias foram aplicadas para diminuição do número de diagonais esbeltas e com baixa inclinação. Primeiramente, pequenas alteraçôes na distorção das diretrizes opostas foram efetuadas suavizando a superfície, mas mantendo sua forma próxima à original. A fim de solucionar o problema da inclinação das diagonais, aumentou-se o número de divisóes da treliça para $8 \mathrm{x} 8$ schemata, o que por um lado resultou na elevação do número de peças mas, por outro, reduziu o vão das barras do banzo inferior de $3750 \mathrm{~mm}$ (1500/4) para $2140 \mathrm{~mm}$ (1500/7). Consequentemente, isso diminuirá a deformação dessas barras e, possivelmente, poderão ser utilizados tubos menos espessos nos banzos. Após essas alterações na forma, algumas diagonais ainda não haviam passado nos limites de esbeltez impostos, o que exigiu queos tipos de tubo fossem alterados, a partir do banco de dados. Nas diagonais, os tubos inicialmente utilizados de $88,9 \mathrm{~mm}$ de diâmetro e 8,0 de espessura foram substituídos por tubos com o mesmo diâmetro, porém com 10,0 mm de espessura. Nesse caso, optou-se por manter as alturas das diagonais inalteradas. Caso fossem diminuídas essas alturas, não haveria a necessidade de substituição dos tubos, ou ainda, sua substituição se daria por tubos menos espessos (Fig. 5).

Se compararmos as treliças apresentadas nas Figuras 4 e 5 , percebemos poucas diferenças em termos de uma intencionalidade formal de projeto. No entanto, essas pequenas alteraçóes representam uma condição muito mais favorável em termos de estabilidade estrutural. Em ambos os casos, admitiram-se conexóes rígidas, e provavelmente aí residem possibilidades para a parametrização de outras condiçóes que conduziráo a uma situação ainda mais 
interessante. É importante ressaltar ainda que apenas duas limitaçóes foram impostas e, sem dúvida, isso representa uma grande redução analítica em termos dos efeitos verificados na prática. No entanto, percebe-se aí uma condição que pode ser explorada pelas plataformas paramétricas de projeto, pois existe um indício de que a implementação desses parâmetros possa contribuir com a elevação da percepção dos projetistas em relação ao comportamento estrutural.

\section{Conclusão}

A investigação computacional proposta aqui pode ser entendida como uma aproximaçáo preliminar de alguns aspectos produtivos às noçôes de parametrização utilizadas atualmente. Um segundo momento para a esta investigação poderia ser a vinculação do sistema proposto com as análises de elementos finitos e com os ensaios com protótipos físicos. De maneira evidente, as possibilidades para a implementação de noçóes sobre o comportamento estrutural em plataformas paramétricas de projeto não se encerram nos dois requisitos mostrados. Ao contrário, outras condiçóes de análise podem ser implementadas nos estágios iniciais do projeto realçando os aspectos produtivos das propostas. Mas a questâo central que merece maiores aproximaçóes científicas reside na investigação de novos modelos para a concepção de estruturas não somente fundamentados nos aspectos da otimizaçáo. Acredita-se que os modelos que emergem de consideraçóes prescientes sobre o comportamento estrutural possibilitem a conjugação, com menores obstáculos, de intencionalidades aparentemente distintas como a complexidade e a eficiência estruturais. Essa perspectiva vai ao encontro da evolução da interação entre a plataforma computacional de projeto e o projetista, que caminha no sentido de elevar a percepção deste último.

\section{Agradecimentos}

Os autores agradecem o apoio financeiro à esta pesquisa:

Processo no 2012/05475-4, Fundação de Amparo à Pesquisa do Estado de São Paulo (FAPESP).

\section{Referências}

Adriaenssen S., Ney L., Bodarwe E., Williams C. (2012). Construction constraints drive the form finding of an irregular meshed steel and glass shell. J Architect Eng, 18(3), 206-13.

\section{ASSOCIAÇÃO BRASILEIRA DE NORMAS TÉCNICAS. NBR} 8800 (2008): Projeto de estruturas de aço e de estruturas mistas de aço e concreto de edifícios. Rio de Janeiro.

ASSOCIAÇÃO BRASILEIRA DE NORMAS TÉCNICAS. NBR/ CB-02 (2011): Projeto de estruturas de aço e de estruturas mistas de aço e concreto de edificaçóes com perfis tubulares. Rio de Janeiro.

Kolarevic, B., Malkawi, A., Eds. (2005). Performative Architecture: Beyond Instrumentality. New York: Routledge.

Richardson J., Adriaenssens, S., Bouillard P., Coelho R. (2013). Coupled form-finding and grid optimization approach for single layer grid shells. Engineering Structures 52, 230-239

Kilian, A., Ochsendorf, J. (2005). Particle-spring systems for structural form-finding. Journal of the International Association for Shell and Spatial Structures, 46(147), 77-84.

Shea, K., Aish, R., Gourtovaia, M. (2005). Towards integrated performance-driven generative design tools. Automation in Construction, 15(2), 253-264.

Pottman, H., Liu, Y., Wallner, J., Bobenko, A. (2007). Geometry of multi-layer freeform structures for architecture. ACM TOG 26, 65(3), 1-11. 